\title{
Kinerja Pendamping Program Keluarga Harapan (PKH) Di Kota Bandar Lampung
}

\author{
Isti Putri Utami ${ }^{1}$, Kordiyana K. Rangga ${ }^{2}$, Helvi Yanfika ${ }^{3}$, Abdul Mutolib ${ }^{4 *}$ \\ ${ }^{1}$ Magister Ilmu Penyuluhan Pembangunan/Pemberdayaan Masyarakat, Program \\ Pascasarjana, Universitas Lampung, Bandar Lampung, Indonesia \\ ${ }^{2,3,4}$ Program Studi Penyuluhan Pertanian, Fakultas Pertanian, Universitas Lampung, Bandar \\ Lampung, Indonesia
}

*Email: amutolib24@yahoo.com

\begin{abstract}
This study aims to determine the level of performance of the Family Hope Program (PKH) assistant in Bandar Lampung City and analyze the factors that influence it. The study was conducted in February-March 2020 with 104 PKH assistants in Bandar Lampung. The analysis method used descriptive and quantitative analysis. Data analysis was performed by multiple linear regression. The results show that the performance level of PKH assistants in Bandar Lamping City is in the moderate classification. This is shown from the results of the work achievements of the assistants in carrying out their duties. In the implementation of participation validation, distribution of assistance, updating data, and reporting of activities, it is known that the assistant has succeeded in carrying out his duties according to the procedure. In the implementation of $P 2 K 2$, assistants have used learning media and have delivered all the materials, but there are some assistants who have not delivered the entire materials. In the implementation of verification of KPM PKH commitments, there are still assistants who do not monitor the visits of KPM PKH assisted in the education component. The results also show that there is an influence between the level of non-formal education, motivation, work discipline, work environment, and perceptions of assistant incentives on the level of performance of assistants. This means that the higher the level of non-formal education, motivation, work discipline, work environment, and perceptions of companion incentives, the higher the level of performance of PKH assistants in Bandar Lampung City.
\end{abstract}

Keywords : assistant performance, performance factors, $\mathrm{PKH}$

\begin{abstract}
Abstrak
Penelitian ini memiliki tujuan untuk mengetahui tingkat kinerja pendamping Program Keluarga Harapan (PKH) di Kota Bandar Lampung serta menganalisis faktor-faktor yang mempengaruhinya. Penelitian dilakukan pada bulan Februari-Maret 2020 dengan responden sebanyak 104 pendamping PKH di Kota Bandar Lampung. Metode analisis menggunakan analisis deskriptif dan kuantitatif. Analisis data dilakukan dengan regresi linear berganda. Berdasarkan hasil penelitian, diketahui bahwa tingkat kinerja pendamping PKH di Kota Bandar Lamping berada pada klasifikasi sedang. Hal tersebut ditunjukkan dari hasil capaian kerja pendamping dalam melaksanakan tugasnya sebagai pendamping PKH. Pada pelaksanaan validasi kepesertaan, penyaluran bantuan, pemutakhiran data, dan pelaporan kegiatan diketahui bahwa pendamping telah berhasil melakukan tugasnya sesuai dengan prosedur. Pada pelaksanaan P2K2, pendamping telah menggunakan media pembelajaran untuk mempermudah pelaksanaan kegiatan dan telah menyampaikan keseluruhan materi, namun masih dapat dijumpai beberapa pendamping yang belum menyampaikan keseluruhan materi tersebut. Pada pelaksanaan verifikasi komitmen KPM PKH, masih terdapat pendamping yang tidak memantau kunjungan KPM PKH dampingannya pada komponen pendidikan. Hasil penelitian juga menunjukkan bahwa terdapat pengaruh antara tingkat pendidikan non formal, motivasi, disiplin kerja, lingkungan kerja, serta persepsi insentif pendamping terhadap tingkat kinerja pendamping. Hal tersebut memiliki makna bahwa semakin tinggi tingkat pendidikan non formal, motivasi, disiplin kerja, lingkungan kerja, dan persepsi terhadap insentif pendamping maka semakin tinggi tingkat kinerja pendamping PKH di Kota Bandar Lampung.
\end{abstract}

Kata kunci : faktor-faktor kinerja, kinerja pendamping, PKH 


\section{Pendahuluan}

Program Keluarga Harapan (PKH) adalah salah satu upaya penanggulangan permasalahan kemiskinan yang memiliki tingkat efektivitas tertinggi dibandingkan dengan program penanggulangan kemiskinan lainnya di Indonesia (Kementerian Sosial Republik Indonesia, 2019). Hal tersebut dikarenakan bantuan tunai bersyarat dan akses layanan pendidikan maupun kesehatan yang diberikan mampu meningkatkan kualitas dan standar hidup Keluarga Penerima Manfaat (KPM) PKH. Meriyanti (2015) juga memperkuat pernyataan tersebut bahwa PKH mampu meningkatkan pengeluaran KPM PKH untuk memenuhi kebutuhan pangan, pakaian, pendidikan anak, maupun kesehatan keluarga.

Program Keluarga Harapan juga memberikan kegiatan pemberdayaan yang disebut dengan kegiatan Pertemuan Peningkatan Kemampuan Keluarga (P2K2). Kegiatan pemberdayaan tersebut bertujuan untuk mencegah terjadinya ketergantungan KPM PKH terhadap bantuan sosial yang diberikan (Kementerian Sosial Republik Indonesia, 2013). Berdasarkan uraian tersebut, maka diharapkan kuota penerima manfaat PKH dapat terus ditingkatkan agar dapat mendukung terjadinya penurunan jumlah penduduk miskin di Indonesia.

Program Keluarga Harapan telah diterapkan di Provinsi Lampung sejak tahun 2016 dengan Kota Bandar Lampung sebagai daerah yang pertama kali menerapkan program tersebut. Pada tahun 2019, telah terdapat 34.444 dari total 76.553 rumah tangga dengan status kesejahteraan terendah di Kota Bandar Lampung yang telah memperoleh bantuan PKH. Artinya sebesar 44.99 persen rumah tangga dengan status kesejahteraan terendah di Kota Bandar Lampung yang telah menerima bantuan PKH (Tim Nasional Percepatan Penanggulangan Kemiskinan, 2019). Sejalan dengan hal tersebut, terdapat penurunan penduduk miskin di Kota Bandar Lampung sejak tahun 2016-2019 yaitu sebanyak 9.3 ribu jiwa (1.44\%) (Badan Pusat Statistik Kota Bandar Lampung, 2020).

Tujuan PKH dapat dicapai dengan melakukan koordinasi yang baik antara sumber daya manusia (SDM) PKH serta pihak-pihak terkait dalam pelaksanaan PKH. Salah satu SDM PKH yang berperan penting untuk mempecepat pencapaian tujuan $\mathrm{PKH}$ adalah pendamping $\mathrm{PKH}$ (Gulo, 2018). Hal ini sesuai dengan pernyataan Direktorat Jenderal Perlindungan dan Jaminan Sosial (2019), yang menyatakan bahwa pendamping PKH sangat dibutuhkan untuk percepatan pencapaian tujuan PKH karena Unit Pelaksana PKH kabupaten/kota tidak bisa mengerjakan sendiri penjangkauan kepada seluruh KPM PKH wilayahnya. Rangga, Darsono, Anantanyu, dan Wijaya (2014), juga menyatakan bahwa peran pendamping sebagai fasilitator sangat menentukan tercapainya tujuan suatu program. Berdasarkan hal tersebut maka kinerja pendamping perlu diukur sehingga dapat mengetahui seberapa baik pendamping dapat melakukan tugasnya dalam mencapai tujuan PKH.

Kinerja pendamping dapat dipengaruhi oleh beberapa faktor seperti tingkat pendidikan, motivasi, insentif, dan lingkungan kerja (Suprihati, 2014). Maharani, Warsono, dan Mustam (2015), juga menyatakan bahwa terdapat hubungan positif antara motivasi dan disiplin kerja seseorang terhadap kinerjanya. Oleh karena itu, penelitian tentang kinerja pendamping serta faktor yang mempengaruhinya perlu dilakukan. Berdasarkan uraian di atas, maka tujuan penelitian ini adalah untuk mengetahui tingkat kinerja pendamping PKH di Kota Bandar lampung, serta menganalisis faktor-faktor yang mempengaruhi kinerja pendamping $\mathrm{PKH}$ di Kota Bandar Lampung.

\section{Metodologi Penelitian}

Lokasi penelitian ini adalah Kota Bandar Lampung atas pertimbangan bahwa Kota Bandar Lampung merupakan kota yang pertama kali melaksanakan PKH di Provinsi Lampung. Penelitian dilaksanakan pada bulan Februari-Maret 2020. Responden penelitian ini adalah 104 pendamping PKH di seluruh kecamatan di Kota Bandar Lampung. Metode penelitian ini adalah metode survei. Data yang digunakan adalah data primer dan sekunder. Data primer diperoleh 
melalui wawancara menggunakan kuesioner, sedangkan data sekunder diperoleh dari literatur yang mendukung penelitian ini.

Metode analisis data yang digunakan adalah analisis deskriptif dan kuantitatif. Analisis deskriptif dilakukan dengan menyederhanakan data ke dalam bentuk yang mudah dipahami untuk menjawab tujuan pertama penelitian. Data dianalisis dengan analisis regresi linear berganda untuk menjawab tujuan kedua penelitian melalui bantuan software SPSS 22. Persamaan analisis regresi berganda yang digunakan pada penelitian ini adalah:

$$
\mathrm{Y}=\mathrm{b}_{1} \mathrm{X}_{1}+\mathrm{b}_{2} \mathrm{X}_{2}+\mathrm{b}_{3} \mathrm{X}_{3}+\mathrm{b}_{4} \mathrm{X}_{4}+\mathrm{b}_{5} \mathrm{X}_{5}+\mathrm{b}_{6} \mathrm{X}_{6}
$$

Keterangan:

$\mathrm{Y}=$ Kinerja pendamping

$\mathrm{b}=$ koefisien variabel

$\mathrm{X}_{1}=$ Tingkat pendidikan non formal

$\mathrm{X}_{2}=$ Motivasi

$\mathrm{X}_{3}=$ Disiplin Kerja

$\mathrm{X}_{4}=$ Lingkungan Kerja

$\mathrm{X}_{5}=$ Hubungan Interpersonal

$\mathrm{X}_{6}=$ Persepsi terhadap Insentif

\section{Hasil dan Pembahasan}

\subsection{Karakteristik Responden}

Secara keseluruhan responden memiliki umur yang berada kisaran usia 28-33 tahun dengan persentase sebesar 49.04 persen dan termasuk ke dalam kategori usia produktif. Tingkat pendidikan formal responden didominasi pada tingkat sarjana yaitu sebesar 92.31 persen. Selain itu, secara keseluruhan jumlah kelompok dampingan pendamping PKH berkisar antara 9-12 kelompok dengan persentase sebesar 56.73 persen. Pembentukan kelompok tersebut bertujuan untuk mengefektifkan kegiatan pemberdayaan KPM PKH yang dikenal dengan kegiatan P2K2.

\subsection{Tingkat Kinerja Pendamping PKH di Kota Bandar Lampung}

Pada penelitian ini, penilaian tingkat kinerja pendamping $\mathrm{PKH}$ di Kota Bandar Lampung mengacu pada Buku Kerja Pendamping dan Operator PKH (Direktorat Jenderal Perlindungan dan Jaminan Sosial, 2015). Salah satu aspek untuk menilai kinerja penyuluh dan pendamping adalah melalui kepuaan sasaran (Nurmayasari et al., 2020 dan Viantimala et 1., 2020). Berdasarkan hal tersebut, maka tingkat kinerja pendamping PKH di Kota Bandar Lampung diukur dengan menggunakan enam indikator yaitu pelaksanaan validasi kepesertaan KPM PKH, penyaluran bantuan sosial, pelaksanaan P2K2, pelaksanaan verifikasi komitmen, pelaksanaan pemutakhiran data, dan pelaporan kegiatan. Berikut ini adalah hasil tingkat kinerja pendamping PKH di Kota Bandar Lampung.

Tabel 1. Tingkat kinerja pendamping PKH di Kota Bandar Lampung

\begin{tabular}{clcc}
\hline Interval (Skor) & \multicolumn{1}{c}{ Klasifikasi } & Jumlah (Orang) & Persentase \\
\hline $21.73-29.64$ & Sangat rendah & 23 & 22.12 \\
$29.65-37.57$ & Rendah & 2 & 1.92 \\
$37.58-45.49$ & Sedang & 20 & 19.23 \\
$45.50-53.41$ & Tinggi & 36 & 34.62 \\
$53.42-61.34$ & Sangat Tinggi & 23 & 22.12 \\
\hline Jumlah & & 104 & 100.00 \\
\hline Rata-rata & 43.83 (Sedang)
\end{tabular}

Sumber: Data yang telah diolah, 2020 
Secara keseluruhan tingkat kinerja pendamping PKH di Kota Bandar Lampung termasuk dalam klasifikasi sedang dengan perolehan skor rata-rata sebesar 43.83. Tingkat kinerja pendamping pada pelaksanaan validasi kepesertaan berada pada klasifikasi tinggi. Hasil di lapangan menunjukkan bahwa secara keseluruhan pendamping telah melakukan validasi kepesertaan KPM PKH seuai dengan prosedur yang ditetapkan oleh Kementerian Sosial Republik Indonesia.

Tingkat kinerja pendamping pada pelaksanaan penyaluran bantuan sosial PKH berada pada klasifikasi sedang. Berdasarkan hasil turun lapang, diketahui bahwa pendamping telah melakukan penyaluran bantuan PKH sesuai dengan prosedur kerja. Artinya, pada pelaksanaan penyaluran bantuan PKH pendamping selalu melakukan persiapan penyaluran bantuan sesuai dengan prosedur, namun belum tepat waktu dalam menyalurkan bantuan tersebut. Ketidaktepatan waktu penyaluran bantuan disebabkan oleh keterlambatan pemerintah pusat untuk mengirimkan dana bantuan sosial kepada KPM PKH.

Tingkat kinerja pendamping pada pelaksanaan P2K2 berada pada klasifikasi sedang. Fakta di lapangan menunjukkan bahwa pendamping lebih sering menyampaikan materi terkait pengelolaan keuangan keluarga, pentingnya kesehatan khususnya bagi ibu hamil dan balita, serta pentingnya mendukung pendidikan anak. Hal tersebut dikarenakan pendamping memiliki pendapat bahwa ketiga materi tersebut yang paling penting dalam mendukung perubahan perilaku KPM PKH menuju kemandirian sehingga lebih terfokus untuk menyampaikan ketiga materi tersebut. Keadaan di lapangan juga menunjukkan bahwa beberapa pendamping telah menggunakan media pembelajaran agar KPM PKH dapat menerima dan menyerap materi yang diberikan dengan baik yaitu berupa laptop dengan menampilkan slide show ataupun memutarkan video-video pendek, modul belajar, serta poster.

Tingkat kinerja pendamping pada pelaksanaan verifikasi komitmen KPM PKH berada pada klasifikasi sedang. Hasil turun lapang menunjukkan bahwa terdapat pendamping yang jarang memantau tingkat kehadiran KPM PKH pada komponen yang mereka akses. Berdasarkan kondisi di lapangan, terdapat pendamping yang tidak meminta absensi sekolah anak KPM PKH untuk melihat tingkat kehadiran anak KPM PKH tersebut pada komponen pendidikan yang diaksesnya. Hal tersebut dikarenakan kurangnya keseriusan pendamping untuk mendata tingkat kehadiran KPM PKH dampingannya pada fasilitas yang tersedia sesuai dengan komponen yang diterima oleh KPM PKH dampingannya.

Tingkat kinerja pendamping pada pelaksanaan pemutakhiran data KPM PKH berada pada klasifikasi sedang. Berdasarkan hasil turun lapang, pendamping lebih fokus untuk memeriksa ada tidaknya perubahan komponen dan perubahan status KPM PKH dampingannya karena menurut pendamping pengecekan perubahan komponen penting untuk dilakukan agar KPM PKH dampingannya dapat menerima bantuan sesuai dengan perubahan komponennya tersebut. Selain itu, pendamping juga beranggapan jika pengecekan perubahan status KPM PKH dampingannya penting untuk dilakukan karena perubahan status KPM PKH merupakan salah satu indikator penentu keberhasilan PKH.

Tingkat kinerja pendamping pada pelaksanaan pelaporan kegiatan berada pada klasifikasi sedang. Hal tersebut terlihat dari pendamping yang telah mengumpulkan laporan akhir kegiatannya cukup sesuai dengan tengat waktu yang diberikan, serta pendamping juga telah membuat catatan kegiatan hariannya.

\subsection{Faktor-faktor yang Mempengaruhi Kinerja Pendamping PKH}

Faktor-faktor yang memiliki pengaruh terhadap kinerja pendamping PKH di Kota Bandar Lampung adalah tingkat pendidikan non formal $\left(\mathrm{X}_{1}\right)$, motivasi $\left(\mathrm{X}_{2}\right)$, disiplin kerja $\left(\mathrm{X}_{3}\right)$, lingkungan kerja $\left(\mathrm{X}_{4}\right)$, serta persepsi pendamping terhadap insentif $\left(\mathrm{X}_{6}\right)$, sedangkan faktor hubungan interpersonal $\left(\mathrm{X}_{5}\right)$ tidak berpengaruh terhadap kinerja pendamping. Berikut ini hasil analisis pada penelitian ini. 
Tabel 2. Hasil analisis regresi linear berganda

\begin{tabular}{cccc}
\hline Variabel & Koefisien Regresi & $\mathrm{T}$ & Sig \\
\hline Konstanta & -2.504 & 0.928 & 0.355 \\
$\mathrm{X}_{1}$ & 2.278 & 3.637 & 0.000 \\
$\mathrm{X}_{2}$ & 0.905 & 2.705 & 0.008 \\
$\mathrm{X}_{3}$ & 0.668 & 2.221 & 0.029 \\
$\mathrm{X}_{4}$ & 0.570 & 2.181 & 0.032 \\
$\mathrm{X}_{5}$ & 0.712 & 1.843 & 0.068 \\
$\mathrm{X}_{6}$ & 1.297 & 4.027 & 0.000 \\
\hline
\end{tabular}

a. Dependent Variable: Kinerja Pendamping

Sumber: Data yang telah diolah, 2020

Berdasarkan hasil analisis, didapatkan persamaan regresi penelitian : $\mathrm{Y}=2.278 \mathrm{X}_{1}+$ $0.905 \mathrm{X}_{2}+0.668 \mathrm{X}_{3}+0.570 \mathrm{X}_{4}+1.297 \mathrm{X}_{6}$. Persamaan tersebut memiliki makna:

1. Tingkat pendidikan non formal berpengaruh secara signifikan terhadap kinerja pendamping. Hasil penelitian ini memperkuat penelitian Putri, Fatchiya, dan Amanah (2016) dan penelitian Yusnita dan Fadhil (2015), bahwa pelatihan (pendidikan non formal) berpengaruh terhadap kinerja seseorang. Hasil penelitian ini juga mendukung pernyataan Yanfika, Rangga, Viantimala, Listiana, dan Rahmat (2020), yang menyatakan jika pemberian pelatihan dapat mendukung adanya peningkatan keterampilan seseorang. Hasil tersebut dikarenakan tingkat pendidikan non formal yang diperoleh pendamping dapat meningkatkan pengetahuan dan keterampilan pendamping sehingga membantu pendamping dalam melaksanakan tugasnya di lapangan.

2. Motivasi berpengaruh secara signifikan terhadap kinerja pendamping. Hasil temuan penelitian ini memperkuat pendapat Ismawanto (2017), jika motivasi berpengaruh secara signifikan terhadap kinerja. Hasil analisis juga mendukung hasil penelitian Prahiawan dan Simbolo (2014), motivasi berpengaruh secara signifikan terhadap kinerja seseorang. Hal itu disebabkan karena terdapat pendamping yang memiliki keinginan kuat untuk mendapatkan prestasi yang lebih baik sehingga ia memiliki hasil kerja yang baik dalam melaksanakan tugasnya.

3. Disiplin kerja berpengaruh secara signifikan terhadap kinerja pendamping. Hasil penelitian ini mendukung penelitian Sanjaya (2015) dan penelitian Pangarso dan Susanti (2016), bahwa disiplin kerja mempengaruhi kinerja seseorang. Hal ini dikarenakan pendamping yang memiliki ketaatan pada peraturan kerjanya maka ia enggan untuk melanggar prosedur kerjanya. Oleh karena itu, pendamping tersebut akan melakukan pekerjaannya sesuai dengan prosedur.

4. Lingkungan kerja pendamping berpengaruh secara signifikan terhadap kinerja pendamping. Hasil temuan mendukung penelitian Rokhilah dan Darmanto (2014) dan juga penelitian Lestary dan Harmon (2017), yang menyatakan bahwa lingkungan kerja berpengaruh secara signifikan terhadap kinerja seseorang. Hal tersebut didasarkan karena adanya fasilitas berupa buku kerja pendamping yang dapat menjadi panduan pendamping untuk melaksanakan tugasnya di lapangan.

5. Hubungan interpersonal pendamping tidak berpengaruh secara signifikan terhadap kinerja pendamping. Hasil temuan penelitian ini menolak pendapat Sidarto (2010), jika hubungan interpersonal berpengaruh terhadap kinerja karyawan. Hal tersebut dikarenakan pendamping lebih sering melaksanakan tugasnya di lapangan dibandingkan di kantor UPPKH Kota Bandar Lampung, sehingga hubungan yang terjalin antar pendamping maupun atasan tidak dapat mempengaruhi pendamping untuk melaksanakan tugasnya di lapangan.

6. Persepsi pendamping terhadap insentif berpengaruh secara signifikan terhadap kinerja pendamping. Hasil temuan penelitian ini mendukung penelitian Fitriadi (2015) serta Yusuf dan Asyhari (2017), bahwa pemberian insentif memiliki pengaruh terhadap kinerja 
seseorang. Kondisi di lapangan juga menunjukkan bahwa pendamping yang memiliki persepsi terhadap insentif baik, maka ia lebih totalitas dalam melakukan tugasnya sebagai pendamping. Hal tersebut dikarenakan pendamping dapat menggunakan insentifnya tersebut untuk pelaksanaan kunjungan di lapangan.

Hasil uji statistik, diketahui nilai f hitung (72.340) > nilai $f$ tabel (2.106). Hasil tersebut memiliki makna bahwa tingkat pendidikan non formal, motivasi, disiplin kerja, lingkungan kerja, hubungan interpersonal, dan persepsi terhadap insentif pendamping secara stimultan berpengaruh signifikan terhadap kinerja pendamping PKH.

Berdasarkan uji statistik, diperoleh nilai koefisien determinasi $\left(\mathrm{R}^{2}\right)$ sebesar 0.817 . Hasil tersebut memiliki makna bahwa sebesar $81.70 \%$ tingkat pendidikan non formal, motivasi, disiplin kerja, lingkungan kerja, hubungan interpersonal, dan persepsi terhadap insentif secara stimultan mempengaruhi kinerja pendamping. Adapun sisanya, yaitu 18.30\% dipengaruhi oleh faktor lainnya yang tidak diteliti dalam penelitian ini.

\section{Kesimpulan}

Tingkat kinerja pendamping PKH di Kota Bandar Lampung secara keseluruhan berada pada klasifikasi sedang, artinya secara keseluruhan pendamping telah melaksanakan tugasnya sesuai dengan prosedur. Meskipun demikian, masih dapat dijumpai pendamping yang belum menyampaikan keseluruhan materi $\mathrm{P} 2 \mathrm{~K} 2$, serta pendamping yang tidak memantau tingkat kehadiran KPM PKH pada komponen yang mereka akses.

Faktor-faktor yang memiliki pengaruh signifikan terhadap kinerja pendamping PKH di Kota Bandar Lampung antara lain tingkat pendidikan non formal, motivasi, disiplin kerja, lingkungan kerja, dan persepsi terhadap insentif pendamping. Oleh karena itu, untuk meningkatkan kinerja pendamping dalam rangka mencapai tujuan PKH maka dapat dilakukan dengan cara meningkatkan pendidikan non formal, motivasi, disiplin kerja, lingkungan kerja, dan insentif pendamping.

\section{Saran}

Berdasarkan hasil penelitian ini, untuk meningkatkan tingkat kinerja pendamping PKH di Kota Bandar Lampung dapat dilakukan dengan cara meningkatkan frekuensi pendidikan non formal seperti Pendidikan atau Pelatihan (Diklat), Bimbingan Pemantapan (Bimtap), dan Bimbingan Teknis (Bimtek) pendamping agar dapat mendukung peningkatan keterampilan pendamping PKH dalam melaksanakan tugasnya. Selain itu, diharapkan agar Dinas Sosial Kota Bandar Lampung dapat memberikan apresiasi terhadap hasil kerja pendamping maupun menyediakan fasilitas kerja pendamping sehingga dapat meningkatkan motivasi dan lingkungan kerja pendamping untuk melakukan pekerjaannya dengan lebih baik lagi.

\section{Ucapan Terimakasih}

Terimakasih kepada Dinas Sosial Kota Bandar Lampung atas koordinasi dan bantuannya sehingga penelitian ini bisa terlaksana.

\section{Daftar Pustaka}

Badan Pusat Statistik Kota Bandar Lampung. 2020. Kota Bandar Lampung dalam Angka. BPS Kota Bandar Lampung. Bandar Lampung.

Direktorat Jenderal Perlindungan dan Jaminan Sosial. 2015. Buku Kerja Pendamping dan Operator $P K H$. Kementerian Sosial RI. Jakarta.

Direktorat Jenderal Perlindungan dan Jaminan Sosial. 2019. Pedoman Pelaksanaan Program Keluarga Harapan. Kementerian Sosial RI. Jakarta.

Faturrochman., Molo, M. 1994. Karakteristik Rumah Tangga Miskin. Jurnal Populasi 5 (1): 74-93.

Fitriadi, R. 2015. Pengaruh Pemberian Insentif terhadap Kinerja Karyawan Distributor Baterai Yuasa (Kasus PT. Riau Indotama Abadi Pekan Baru). Jurnal Jom FISIP 2 (1): 1-9. 
Gulo, N. J. 2018. Analisis Kinerja Pendamping Program Keluarga Harapan dalam Upaya

Pengentasan Kemiskinan di Kota Medan. Tesis, Program Pasca Sarjana Magister Manajemen, Universitas Sumatera Utara. Medan.

Ismawanto, T. 2017. Pengaruh Kepemimpinan, Motivasi, dan Kompetensi terhadap Kinerja Organisasi Kesiswaan. Jurnal Sosial Humaniora dan Pendidikan 2(1): 19-26.

Kementerian Sosial Republik Indonesia. 2019. Pedoman Pelaksanaan Program Keluarga Harapan (PKH). Kementerian Sosial. Jakarta.

Kementerian Sosial Republik Indonesia. 2013. Pedoman Umum PKH. Kementerian Sosial. Jakarta.

Lestary, L., Harmon. 2017. Pengaruh Lingkungan Kerja terhadap Kinerja Karyawan. Jurnal Riset Bisnis dan Investasi 3 (2): 94-103.

Maharani, A., Warsono, H., Mustam, M. 2015. Analisis Kinerja Pegawai pada Dinas Tenaga Kerja, Transmigrasi Dan Kependudukan Provinsi Jawa Tengah. Journal of Public Policy and Management 4 (3): 1-11.

Meriyanti, N. K. 2015. Pengaruh Program Indeks Pembangunan Manusia (IPM) terhadap Pengentasan Kemiskinan di Kecamatan Buleleng Tahun 2011-2014. Jurnal Pendidikan Ekonomi 3 (1): 5262.

Nurmayasari, I. Viantimala, B. and Gultom, DT. Yanfika, H. and Mutolib, A. 2020. Partisipasi dan Kepuasan Petani terhadap Kinerja Penyuluh Pertanian di Kecamatan Palas Kabupaten Lampung Selatan. Mimbar Agribisnis, 6 (1). pp. 448-459.

Pangarso, A., Susanti, P. I. 2016. Pengaruh Disiplin Kerja terhadap Kinerja Pegawai di Biro Pelayanan Sosial Dasar Sekretariat Daerah Provinsi Jawa Barat. Jurnal Manajemen Teori dan Terapan 9 (2): $145-160$.

Prahiawan, W., Simbolon, N. 2014. Pengaruh Motivasi Intrinsik dan Lingkungan Kerja terhadap Kinerja Karyawan pada PT Intimas Lestari Nusantara. Jurnal Ekonomi 3 (1): 35-41.

Putri, I, W., Fatchiya, A., Amanah, S. 2016. Pengaruh Pelatihan Non Teknis terhadap Kinerja Penyuluh Pertanian BP4K di Kabupaten Bungo Provinsi Jambi. Jurnal Penyuluhan 12 (1): 4350.

Rangga, K. K., Darsono., Anantanyu, S., Wijaya, M. 2014. The Participation of Micro Business Affinity Group Members in the Implementation of Food Self-Sufficienty Action Program In Lampung Province. Academic Research International 5(3): 112-122.

Rokhilah., Darmanto, S. 2014. Pengaruh Kompetensi, Motivasi, dan Lingkungan Kerja terhadap Kinerja Penyuluh Lapangan Program Keluarga Berencana (PLKB) di Kabupaten Pemalang. Jurnal Media Ekonomi dan Manajemen 29 (1): 68-82.

Sanjaya, M. T. R. 2015. Pengaruh Disiplin Kerja dan Motivasi Kerja terhadap Kinerja Karyawan pada Hotel Ros In Yogyakarta. Skripsi. Program Studi Manajemen. Universitas Negeri Yogyakarta. Yogyakarta.

Sidarto, A. H. 2010. Pengaruh Hubungan Interpersonal, Motivasi Kerja, dan Dukungan Sosial terhadap Kinerja Karyawan PT. Warna Dunia di Semarang. Skripsi. Program Studi Manajemen. Universitas Katolik Soegijapranata. Semarang.

Suprihati. 2014. Analisis Faktor-Faktor yang Mempengaruhi Kinerja Karyawan Perusahaan Sari Jati Di Sragen. Jurnal Paradigma 12 (1): 93-112.

Tim Nasional Percepatan Penanggulangan Kemiskinan. 2019. Sebaran Data Terpadu Kesejahteraan Sosial Kota Bandar Lampung. http://bdt.tnp2k.go.id/sebaran/. Diakses pada 16 November 2020 pukul 09.00 WIB.

Viantimala, B. Yanfika, H. Mutolib, A. Listiana, I. dan Effendi, I. 2020. Kinerja Penyuluh dan Partisipasi Petani dalam Kegiatan Penyuluhan Pertanian di Kecamatan Kotagajah Kabupaten Lampung Tengah. Journal of Food Systems \& Agribusiness, 4(1): 9-16.

Yanfika, H., Rangga, K.K., Viantimala, B., Listiana, L., Rahmat, A. 2020. Evaluation of the Success of Programs and Strategy for Sustainable Coastal Community Development in Tanggamus Regency. Journal of Physics: Conference Series 1467 012026: 1-9.

Yusnita, N., Fadhil, F. 2015. Pengaruh Pelatihan Karyawan terhadap Kinerja Karyawan pada CV Cibalung Happy Land Bogor. Jurnal Ilmiah Manajemen Fakultas Ekonomi 1(1): 1-5.

Yusuf. M., Asyhari, A. 2017. Pengaruh Pemberian Insentif terhadap Kinerja Karyawan pada Perusahaan Pabrik Roti Lala di Desa Bajo Indah Kecamatan Soropia Kabupaten Konawe. Jurnal Mega Aktiva 6 (2): 83-88. 